\title{
Silencing neuroglobin enhances neuronal vulnerability to oxidative injury by down-regulating 14-3-3y
}

\author{
Shi-qiao YE* , Xin-yu ZHOU*, Xiao-jing LAI, Li ZHENG, Xiao-qian CHEN* \\ Department of Pathophysiology, Tongji Medical College; Key Laboratory of Neurological Diseases (HUST), the Ministry of Education; \\ Huazhong University of Science and Technology, Wuhan 430030, China
}

\begin{abstract}
Aim: To explore the protective role and mechanism of endogenous neuroglobin (Ngb) in neuronal cells under oxidative stress.
Methods: A stable N2a neuroblastoma cell line expressing the Ngb-siRNA plasmid (N2a/Ngb-siRNA) was established by neomycin screening. Reverse transcription (RT)-PCR and Western blot analysis were used to detect Ngb gene and protein levels. Hydrogen peroxide was used to induce oxidative stress in N2a cells. Cytotoxicity and cell viability were measured by lactate dehydrogenase (LDH) and WST-8 assays. Apoptotic cells were detected by Hoechst staining.

Results: Cotransfection of Ngb-siRNA with Ngb-GFP plasmids suppressed the expression of Ngb-GFP in N2a cells. RT-PCR and Western blot analysis showed that the expression of endogenous Ngb was successfully knocked down to about 20\% in N2a/Ngb-siRNA cells compared with control cells. A WST-8 assay demonstrated that viability was significantly decreased in N2a/Ngb-siRNA cells and N2a cells transiently transfected with Ngb-siRNA plasmids compared with controls following hydrogen peroxide treatment. An LDH assay demonstrated a time-dependent increase in the death of Ngb-siRNA-transfected N2a cells following hydrogen peroxide treatment. Hoechst staining demonstrated that the quantity of apoptotic cells among N2a/Ngb-siRNA cells following hydrogen peroxide treatment significantly increased compared with controls. In N2a/Ngb-siRNA cells, the expression level of activated caspase-3 significantly increased, whereas the expression of 14-3-3y decreased compared with that of N2a/vec cells. Transfection of 14-3-3y plasmids significantly enhanced the viability of N2a/Ngb-siRNA cells following hydrogen peroxide treatment compared with vector controls. Conclusion: Ngb contributes to neuronal defensive machinery against oxidative injuries by regulating 14-3-3y expression.
\end{abstract}

Keywords: neuroglobin; siRNA; $\mathrm{H}_{2} \mathrm{O}_{2}$; 14-3-3y; oxidative stress; N2a cells

Acta Pharmacologica Sinica (2009) 30: 913-918; doi: 10.1038/aps.2009.70

\section{Introduction}

Neuroglobin $(\mathrm{Ngb})$, the first hexacoordinate hemoglobin $(\mathrm{h} \times \mathrm{Hb})$ identified in vertebrates, is a novel member of the globin superfamily that exists predominantly in the brain ${ }^{[1]}$ and retina ${ }^{[2]}$. The binding affinity of $\mathrm{Ngb}$ to $\mathrm{O}_{2}$ is similar to that of myoglobin $(\mathrm{Mb})$ and thus is much higher than that of $\mathrm{Hb}^{[1]}$. Therefore, an attractive hypothesis is that $\mathrm{Ngb}$ might store or transport $\mathrm{O}_{2}$ in the brain as $\mathrm{Mb}$ does in the muscle ${ }^{[3]}$. However, the concentration of $\mathrm{Ngb}$ in the brain is much lower than that of $\mathrm{Mb}$ in the muscle ${ }^{[1]}$. Moreover, the hexacoordinated nature of the heme in $\mathrm{Ngb}$ makes the release of oxygen difficult ${ }^{[4]}$. To date, whether Ngb plays such a role remains unclear $^{[5]}$.

\footnotetext{
"The two authors contributed equally to this paper.

*To whom correspondence should be addressed.

E-mail chenxq@mails.tjmu.edu.cn

Received 2008-12-08 Accepted 2009-04-17
}

It has also been proposed that $\mathrm{Ngb}$ functions as a nitric oxide (NO) or reactive oxygen species scavenger, oxygen sensor and signal transduction regulator ${ }^{[5,6]}$. Neuroglobin binds and reacts to $\mathrm{NO}$ and $\mathrm{H}_{2} \mathrm{O}_{2}$ without cytotoxic ferryl protein generation $^{[7]}$. However, $\mathrm{Ngb}$ is devoid of $\mathrm{O}_{2}$ and $\mathrm{NO}$ reductase activities $^{[8]}$. The expression of $\mathrm{Ngb}$ in most areas of the brain does not colocalize with neuronal nitric oxide synthase ${ }^{[9]}$. In $\mathrm{Ngb}$-transgenic mice, the expression of endothelial nitric oxide synthase increases ${ }^{[10]}$. Therefore, determining whether $\mathrm{NO}$-scavenging is an important physiological function of $\mathrm{Ngb}$ in the brain requires further study. The expression of $\mathrm{Ngb}$ should be sensitive to changes in oxygen concentration if it is an oxygen sensor. Indeed, the expression of $\mathrm{Ngb}$ is upregulated by severe hypoxia ${ }^{[11,12]}$. However, no significant changes in $\mathrm{Ngb}$ expression have been observed in the adult mouse brain in response to chronic hypoxia ${ }^{[13,14]}$. In goldfish, which can survive in aquatic environments with low oxygen partial pressures, the expression of $\mathrm{Ngb}$ is also not significantly 
altered by prolonged hypoxia exposure $\mathrm{e}^{[15]}$. This evidence argues against the role of $\mathrm{Ngb}$ as an important oxygen sensor in vivo. In addition to small molecules, Ngb binds to G-proteins and acts as a guanine nucleotide dissociation inhibitor, suggesting that $\mathrm{Ngb}$ may mediate intracellular signaling ${ }^{[16,17]}$.

Another proposed function of $\mathrm{Ngb}$ is the protection of neuronal cells from various pathological insults. Overexpression of $\mathrm{Ngb}$ prevents cell death from hypoxia, ischemia, $\mathrm{NO}$, amyloid beta, and $\mathrm{H}_{2} \mathrm{O}_{2}$ insults ${ }^{[11,18-20]}$. However, the administration of penetrating $\mathrm{Ngb}$ directly to SH-SY5Y cells does not confer protection from oxygen and glucose deprivation ${ }^{[21]}$. In Ngb-transgenic mice, although infarct volume is reduced, long-term improvement in limb deficits after stroke does not occur ${ }^{[22]}$. We previously reported that $\mathrm{Ngb}$ gene expression is not altered in N2a cells following $\mathrm{H}_{2} \mathrm{O}_{2}$ treatment ${ }^{[23]}$. These studies argue against the proposed protective role of $\mathrm{Ngb}$. Here, we address the protective role and mechanisms of endogenous $\mathrm{Ngb}$ in response to $\mathrm{H}_{2} \mathrm{O}_{2}$ treatment by knocking down Ngb in N2a cells.

\section{Materials and methods}

\section{Ngb-siRNA plasmid construction and identification}

Ngb siRNA expression vectors (named Ngb-siRNA) targeted to different regions of mouse Ngb cDNA (gi:18999491) were constructed using a GFP-expressing siRNA vector ( $\mathrm{p}-\mathrm{Gen}$ esil-1, Wuhan Genesil Biotechnology, China), as previously reported $^{[23]}$. The efficiency of Ngb-siRNA plasmids was confirmed by cotransfecting Ngb-siRNA and p-Ngb-EGFP plasmids ${ }^{[18]}$ at a ratio of 4:1 into N2a cells using LipofectAMINE ${ }^{\mathrm{TM}}$ 2000 reagent (Invitrogen Life Technology, USA). All constructs were confirmed by DNA sequencing.

\section{Stable N2a/Ngb-siRNA cell line}

N2a cells were cultured with Dulbecco's modified Eagle's medium (DMEM)/Opti-MEM $(v / v=1: 1) / 5 \%(v / v)$ fetal bovine serum (FBS) (GIBCO BRL, Life Technologies, USA) in an incubator (Precision Scientific, USA) at $37{ }^{\circ} \mathrm{C}$ with $95 \%$ air $/ 5 \%$ $\mathrm{CO}_{2}(v / v)$ and $95 \%$ humidity, as reported previously ${ }^{[23]}$. N2a cells were transfected with Ngb-siRNA plasmids or control vectors, and stable cell lines were screened using a neomycin antibiotic (Sigma, USA) starting at a concentration of 800 $\mu \mathrm{g} / \mathrm{mL}$. The concentration of neomycin antibiotic was gradually reduced to a final concentration of $200 \mu \mathrm{g} / \mathrm{mL}$ within two weeks. Stable N2a cell lines expressing neomycin-resistant Ngb-siRNA (N2a/Ngb-siRNA) or control plasmids (N2a/vec) were obtained by subcloning. The cells were maintained in N2a medium plus neomycin antibiotic $(200 \mu \mathrm{g} / \mathrm{mL})$, and the medium was changed every 2 or 3 days. N2a cells within 50 passages were used in all experiments.

\section{RT-PCR}

The total RNA was isolated from N2a cells using TRIZOL ${ }^{\oplus}$ reagent according to the manufacturer's protocol (Invitrogen Life Technology, USA). The total RNA ( $2 \mu \mathrm{g})$ was then used to perform RT using M-MLV transcriptase (Promega, USA), oligo $\left(\mathrm{dT}_{15}\right)$ primer (Promega, USA) and a total volume of 25 $\mu \mathrm{L}$. Semi-quantitative PCR, 28 cycles of $94{ }^{\circ} \mathrm{C}, 45 \mathrm{~s} ; 60^{\circ} \mathrm{C}$, $45 \mathrm{~s} ; 72{ }^{\circ} \mathrm{C}, 45 \mathrm{~s}$ plus a final extension at $72^{\circ} \mathrm{C}$ for $10 \mathrm{~min}$, was performed as previously reported, using $\beta$-actin as an internal control ${ }^{[23,24]}$. The primers used in PCR were Ngb: $5^{\prime}$-ctctggaacatggcactgtc- $3^{\prime}$ and $5^{\prime}$-gcactggctcgtctcttact- $3^{\prime} ; \beta$-actin: $5^{\prime}$-cagccttccttcttgggtat- $3^{\prime}$ and $5^{\prime}$-gctcagtaacagtccgccta- $3^{\prime}$; and 14-3-3y: $5^{\prime}$-gttggtctggctcttcatcat-3' and $5^{\prime}$-aggtgcagagtagacttgggtg- $3^{\prime}$. All PCR products were confirmed by DNA sequencing.

\section{Western blot analysis}

Cell extracts were prepared and Western blot analysis was performed, as previously described ${ }^{[2,25]}$. Briefly, 10-50 $\mu \mathrm{g}$ of total protein was resolved on $12 \%-15 \%$ reducing SDS-PAGE gels and electrophoretically transferred to nitrocellulose membranes. The membranes were blocked with $5 \%(w / v)$ nonfat dried milk in TBST buffer [0.1 mol/L Tris- $\mathrm{HCl}, \mathrm{pH}$ 8.0, 0.9\% $(w / v) \mathrm{NaCl}$, and $0.1 \%(v / v)$ Tween-20] and probed with rabbit polyclonal antibodies to Ngb (Santa Cruz Biotechnology, USA) and 14-3-3ץ (Immuno-Biological Laboratories, Japan) and mouse monoclonal antibody to $\beta$-actin (Santa Cruz Biotechnology, USA) in TBST overnight at $4{ }^{\circ} \mathrm{C}$. After incubation with corresponding HRP-conjugate secondary antibodies (Chemicon International, USA), antigens were detected using a chemiluminescence kit (Amersham, France).

\section{Cytotoxicity assays}

$\mathrm{N} 2 \mathrm{a} / \mathrm{Ngb}$-siRNA and N2a/vec cells were seeded in 96-wellplates at a density of 50000 cells $/ 100 \mu \mathrm{L}$ per well. Twentyfour hours after incubation, cells were treated with hydrogen peroxide ${ }^{[23]}$. An LDH assay was performed using a kit (Promega, USA). The WST-8 cell viability assay was performed using a Cell Counting Kit-8 (CCK-8) (Dojindo Laboratories, Japan) ${ }^{[26]}$. The absorbance for the LDH and WST- 8 assays was determined at $492 \mathrm{~nm}$ and $450 \mathrm{~nm}$, respectively, using a microtiter plate reader (Synergy 2, BioTek, USA). Cell death and viability were calculated according to the formula provided by the manufacturers.

\section{Identification of apoptosis by Hoechst staining}

Cell cultures were prepared and Hoechst staining was performed as previously reported ${ }^{[25]}$. Cultures of N2a/NgbsiRNA and N2a/vec were fixed with $4 \%$ paraformaldehyde for 30 min. After being washed twice with PBS, Hoechst 33258 was used to stain the nuclei for $5 \mathrm{~min}$ at room temperature. After being washed five times with PBS, micrographs were taken with a conventional fluorescent microscope.

\section{Statistical analysis}

All data are presented as means \pm SEM of at least three individual experiments. RT-PCR and Western blot results were quantified by measuring the band intensity using a densitometer. The relative expression levels of $\mathrm{Ngb}, 14-3-3 \gamma$, and caspase- 3 were normalized to those of $\beta$-actin and compared with controls. $P<0.05$ and $P<0.01$ were considered significant 
compared with controls by Student's unpaired $t$-test.

\section{Results}

The expression of endogenous Ngb is efficiently knocked down in N2a/Ngb-siRNA neuroblastoma cells

To explore the biological function of neuroglobin, we used the siRNA technique to knock down the expression of endogenous Ngb in N2a cells. Three Ngb-siRNA expression vectors were constructed. The Ngb-siRNA plasmids were cotransfected with p-Ngb-EGFP-N1 plasmids ${ }^{[18]}$ into N2a cells to verify their inhibitory efficiency. The Ngb-siRNA plasmid targeting the gtgatgctagtgattgatttca sequence within the $\mathrm{Ngb}$ cDNA inhibited the expression of the Ngb-GFP fusion protein (green under the fluorescent microscope) most effectively (Figure 1A). This effective Ngb-siRNA plasmid and control vector (p-Genesil-1) were then transfected into N2a cells to establish stable N2a/Ngb-siRNA and N2a/vec cell lines by neomycin screening. The RT-PCR results (Figure 1B) showed that the expression level of Ngb mRNA in N2a/Ngb-siRNA (lane 2) decreased (17.9\%) compared with that of N2a/p-Genesil-1 (lane 3). A p-Ngb-EGFP-N1 plasmid was used as a positive control in the PCR. Furthermore, the results of the Western blot analysis show that the expression level of endogenous $\mathrm{Ngb}$ protein also decreased $(21.5 \%)$ in $\mathrm{N} 2 \mathrm{a} / \mathrm{Ngb}$-siRNA cells (Figure 1C). A statistical analysis demonstrates that the expression levels of $\mathrm{Ngb}$ mRNA and protein significantly decreased in N2a/Ngb-siRNA cells. These results together demonstrate that the expression of $\mathrm{Ngb}$ was efficiently suppressed in N2a/Ngb-siRNA cells.

Suppressing endogenous Ngb enhances neuronal vulnerability to oxidative stress-induced cell injury

N2a/Ngb-siRNA and N2a/p-Genesil-1 cells were exposed to $\mathrm{H}_{2} \mathrm{O}_{2}$. Cell viability was calculated by measuring the activity of dehydrogenase in living cells with a WST-8 assay ${ }^{[26]}$. Both $\mathrm{N} 2 \mathrm{a} / \mathrm{Ngb}$-siRNA and N2a/vec cells showed a concentrationdependent decrease in cell viability following $\mathrm{H}_{2} \mathrm{O}_{2}$ treatment (Figure 2A). Cell viability was significantly decreased in N2a/ $\mathrm{Ngb}$-siRNA cells compared with $\mathrm{N} 2 \mathrm{a}$ /vec cells following 150 and $300 \mu \mathrm{mol} / \mathrm{L}$ treatments with $\mathrm{H}_{2} \mathrm{O}_{2}$ (Figure 2A). We then counted the apoptotic cells, which possessed shrunken and condensed nuclei visible with Hoechst staining, as previously reported $^{[18]}$. After treatment with $150 \mu \mathrm{mol} / \mathrm{L}$ of $\mathrm{H}_{2} \mathrm{O}_{2}$ for $12 \mathrm{~h}$, apoptotic nuclei increased in $\mathrm{N} 2 \mathrm{a} / \mathrm{Ngb}$-siRNA cells $(50.8 \%)$ (indicated by arrow head, Figure 2B) compared with N2a/vec cells $(20.2 \%)$.

To further confirm the protective role of endogenous $\mathrm{Ngb}$ from oxidative stress, we knocked down $\mathrm{Ngb}$ expression in N2a cells by transient transfection with Ngb-siRNA plasmids. Transfection of Ngb-siRNA plasmids into N2a cells significantly decreased cell viability following 150 and $250 \mu \mathrm{mol} / \mathrm{L}$ of $\mathrm{H}_{2} \mathrm{O}_{2}$ incubation (Figure 2C). We then determined the time window over which $\mathrm{Ngb}$ exerts its protection. A time-dependent increase in injury of both $\mathrm{N} 2 \mathrm{a} / \mathrm{vec}$ and N2a/Ngb-siRNA cells, measured by an LDH assay, was seen following 150 $\mu \mathrm{mol} / \mathrm{L}$ of $\mathrm{H}_{2} \mathrm{O}_{2}$ incubation (Figure 2D). A statistical analysis
A
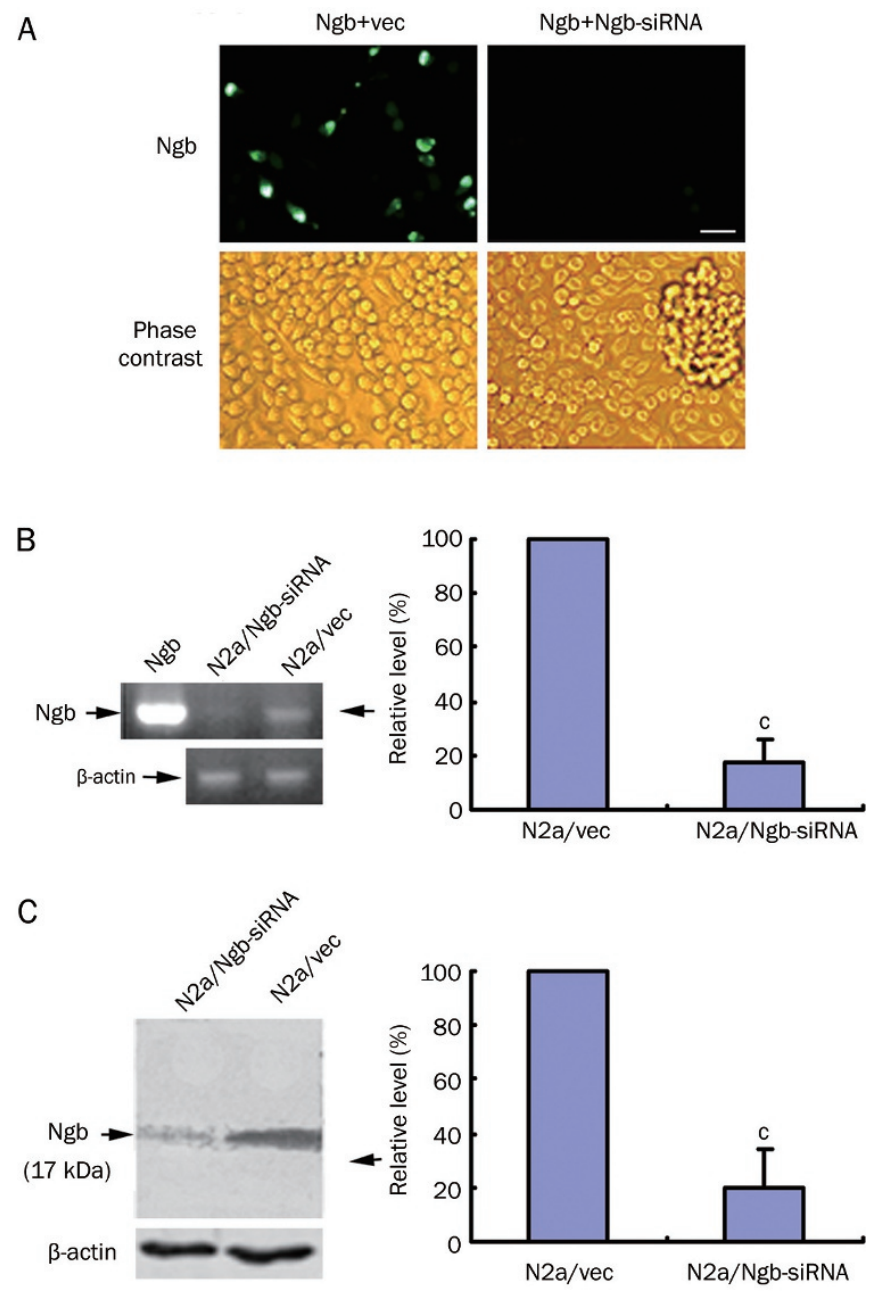

Figure 1. Knock-down of Ngb in N2a neuroblastoma cells. (A) Ngb-siRNA plasmids were co-transfected with $\mathrm{p}$-Ngb-EGFP-N1 plasmids into N2a cells. The expression of Ngb-GFP fusion protein (green) was suppressed after Ngb-siRNA transfection (right panel). Bar, $20 \mu \mathrm{m}$. (B) Ngb-siRNA and control plasmids (vec) were transfected into N2a cells and stable cell lines were established by neomycin selection. A representative RT-PCR result shows that the expression level of Ngb mRNA decreased in Ngb-siRNA transfected (N2a/Ngb-siRNA) cells compared with vector transfected $(\mathrm{N} 2 \mathrm{a} / \mathrm{vec})$ cells. $\beta$-actin served as an internal control and p-Ngb-EGFP-N1 plasmids served as positive controls. (C) A representative Western blot analysis shows decreased expression of Ngb protein in N2a/Ngb-siRNA cells. $\beta$-actin served as an internal control. All statistical results are expressed as means \pm SEM from three independent experiments. ${ }^{c} P<0.01$ vs $\mathrm{N} 2 \mathrm{a} / \mathrm{vec}$.

demonstrates that cell death was significantly increased in $\mathrm{N} 2 \mathrm{a} / \mathrm{Ngb}$-siRNA cells compared with $\mathrm{N} 2 \mathrm{a} / \mathrm{vec}$ cells after 0.5, $1,2,3,4$, and $5 \mathrm{~h}$ of $\mathrm{H}_{2} \mathrm{O}_{2}$ treatment (Figure 2D). These data together demonstrate that endogenous $\mathrm{Ngb}$ can protect neuronal cell against oxidative insults.

Suppressing Ngb induces caspase-3 activation and downregulates 14-3-3y expression

To investigate whether endogenous $\mathrm{Ngb}$ is involved in apop- 
A

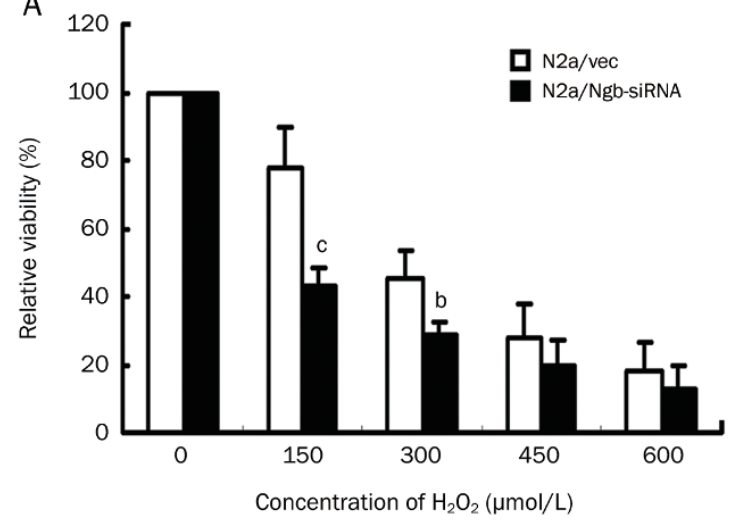

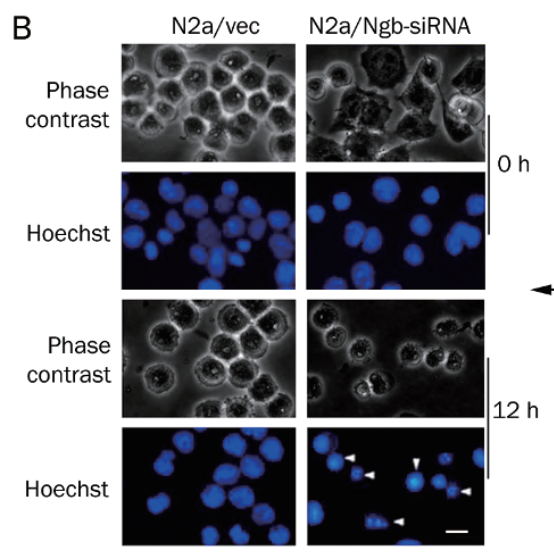

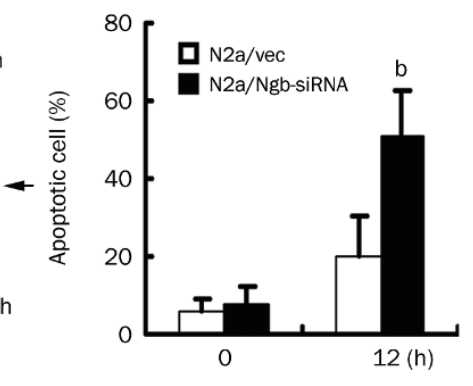

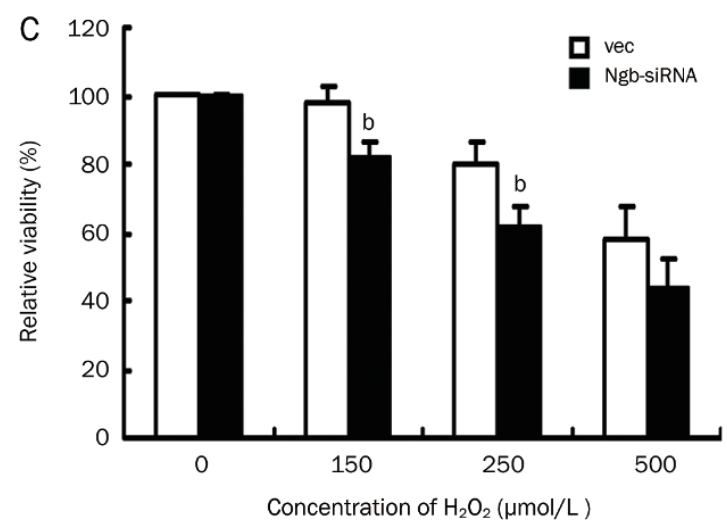

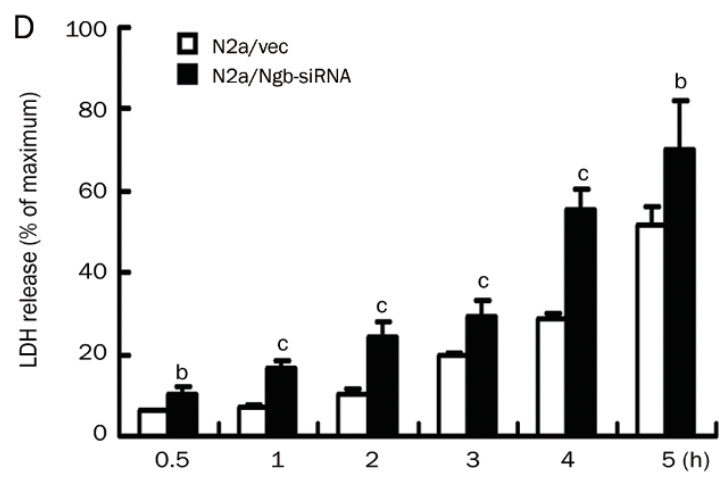

Figure 2. Silencing of Ngb enhances cell death following $\mathrm{H}_{2} \mathrm{O}_{2}$ treatment. (A) N2a/Ngb-siRNA and N2a/vec cells were exposed to various concentration of $\mathrm{H}_{2} \mathrm{O}_{2}$ for $12 \mathrm{~h}$. A WST-8 assay demonstrates that the viability of N2a/Ngb-siRNA cells significantly decreased compared with N2a/vec cells following treatment with 150 and $300 \mu \mathrm{mol} / \mathrm{L}$ of $\mathrm{H}_{2} \mathrm{O}_{2}$. (B) N2a/Ngb-siRNA and N2a/vec cells were exposed to $150 \mu \mathrm{mol} / \mathrm{L}$ of $\mathrm{H}_{2} \mathrm{O}_{2}$ for $12 \mathrm{~h}$ and the nuclei were stained with Hoechst 33258. Apoptotic nuclei (condensed heavy staining nuclei indicated by arrow heads) increased in N2a/Ngb-siRNA cells after $12 \mathrm{~h}$ of $\mathrm{H}_{2} \mathrm{O}_{2}$ incubation. Bar, $10 \mu \mathrm{m}$. (C) Wild-type N2a cells were transiently transfected with Ngb-siRNA plasmids or control vectors and exposed to various concentrations of $\mathrm{H}_{2} \mathrm{O}_{2}$ for $12 \mathrm{~h}$. A WST-8 assay demonstrates that the viability of N2a cells after Ngb-siRNA transfection significantly decreased following treatments with 150 and $250 \mu \mathrm{mol} / \mathrm{L}$ of $\mathrm{H}_{2} \mathrm{O}_{2}$ compared with N2a cells transfected with vectors. (D) N2a/Ngb-siRNA and N2a/vec cells were exposed to $150 \mu \mathrm{mol} / \mathrm{L}$ of $\mathrm{H}_{2} \mathrm{O}_{2}$ for $0.5,1,2,3,4$, and $5 \mathrm{~h}$. An LDH assay demonstrates that cell death significantly increased in N2a/Ngb-siRNA cells. All statistical results are expressed as means \pm SEM from at least three independent experiments. ${ }^{b} P<0.05,{ }^{c} P<0.01$ vs corresponding control cells.

totic machinery, we analyzed the level of activated caspapse-3, which is the molecular marker for activation of the apoptotic signaling pathway. Western blot analysis demonstrated that the level of cleaved caspase-3 in N2a/Ngb-siRNA cells was 1.7 fold and significantly higher than the level in N2a/vec cells (Figure $3 \mathrm{~A}, P<0.01$ ). The activation of caspase-3 after $\mathrm{Ngb}$ silencing indicates that the overall effect of endogenous $\mathrm{Ngb}$ in neuronal cells is anti-apoptotic.

We then investigated the mechanism by which Ngb inhibited caspase-3 activation. 14-3-3 proteins exist predominantly in the brain and mediate essential apoptotic signaling pathways ${ }^{[28,29]}$. We have previously reported that $14-3-3 \gamma$ is up-regulated and protects astrocytes from ischemia-induced apoptosis ${ }^{[24,25]}$. We compared the expression of 14-3-3y transcripts (Figure 3B) and proteins (Figure $3 \mathrm{C}$ ) in N2a/NgbsiRNA and N2a/vec cells. The results of RT-PCR show that the expression level of $14-3-3 \gamma$ transcripts decreased $(25.4 \%)$ in N2a/Ngb-siRNA cells compared with N2a/vec cells (Fig- ure 3B). A statistical analysis demonstrates that the level of $14-3-3 y$ transcripts was significantly lower than that of controls (Figure 3B). A Western blot analysis showed that the expression level of $14-3-3 \gamma$ protein decreased $(28.8 \%)$ in N2a/ Ngb-siRNA cells compared with N2a/vec cells (Figure 3C). We further confirmed the protective role of $14-3-3 \gamma$ from oxidative stress by transfecting 14-3-3ץ plasmids ${ }^{[24]}$ into N2a/ Ngb-siRNA cells. A WST-8 assay demonstrated that overexpression of $14-3-3 \gamma$ in N2a/Ngb-siRNA cells significantly enhanced cell viability following treatment with $150 \mu \mathrm{mol} / \mathrm{L}$ of $\mathrm{H}_{2} \mathrm{O}_{2}$ compared with vector controls (Figure 3D).

\section{Discussion}

Neuroglobin may serve as an oxygen store/transporter, gas sensor, reactive oxygen species scavenger, and signal transduction modulator based on its ability to bind to $\mathrm{O}_{2}, \mathrm{NO}, \mathrm{H}_{2} \mathrm{O}_{2}$, and G-protein ${ }^{[3,6]}$. However, there has been no clear physiological function that can be assigned to Ngb until now. Here, 

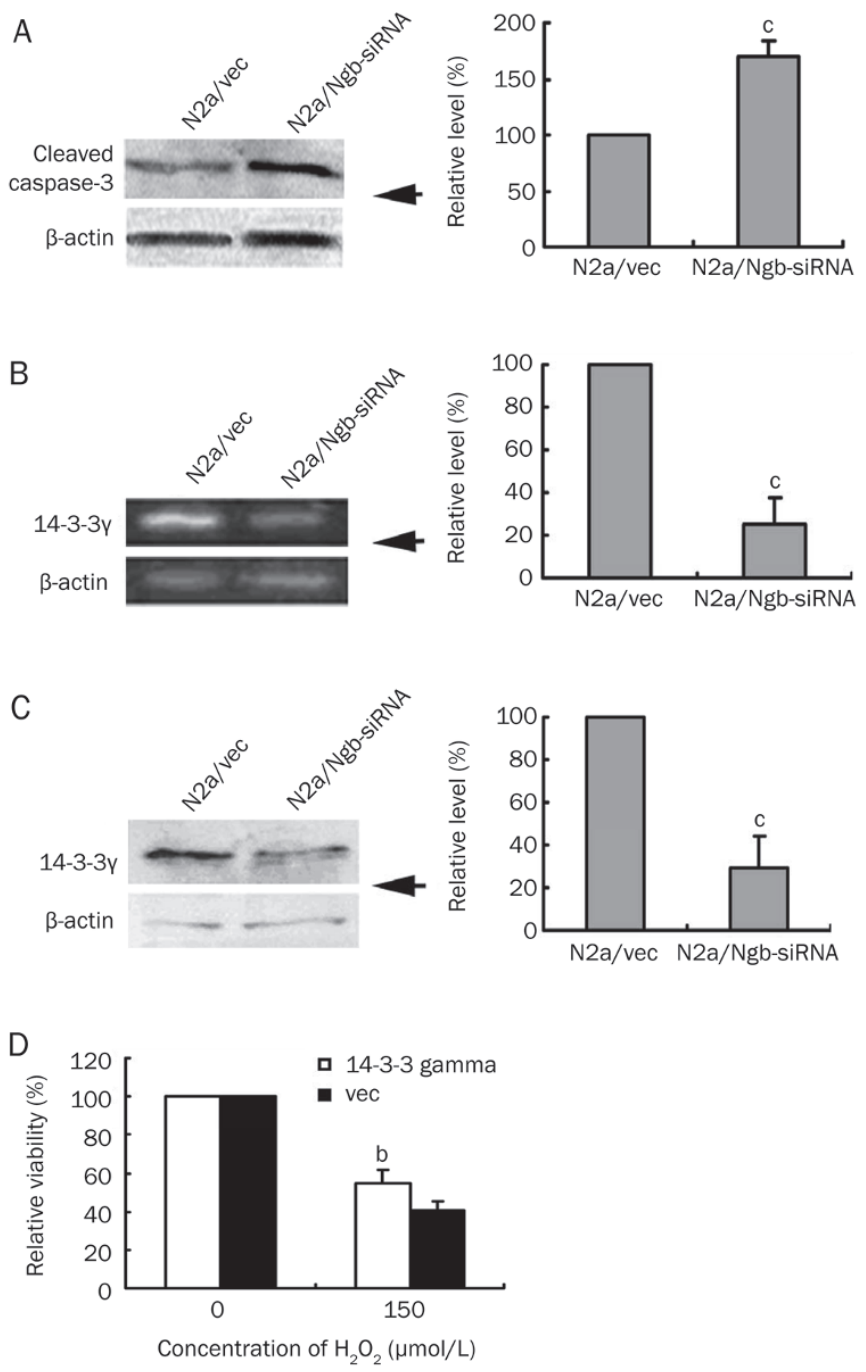

Figure 3. Silencing of Ngb induces caspase-3 activation and inhibits 14-3-3y expression. (A) A Western blot analysis demonstrates that cleaved caspase-3 increased significantly in N2a/Ngb-siRNA cells. (B) RT-PCR demonstrates that the expression level of 14-3-3y mRNA decreased significantly in N2a/Ngb-siRNA cells. (C) Western blot analysis demonstrates that the expression of 14-3-3y protein decreased significantly in N2a/Ngb-siRNA cells. (D) A WST-8 assay demonstrates that overexpression of $14-3-3 y$ significantly enhanced the viability of $\mathrm{N} 2 \mathrm{a} / \mathrm{Ngb}$-siRNA cells following treatment with $150 \mu \mathrm{mol} / \mathrm{L}$ of $\mathrm{H}_{2} \mathrm{O}_{2}$ for $12 \mathrm{~h}$ compared with vector controls ( $\mathrm{p}$-EGFP-N1). All statistical results are expressed as means \pm SEM from three independent experiments. ${ }^{\mathrm{b}} P<0.05,{ }^{\mathrm{c}} P<0.01$ vs corresponding control cells.

we successfully knocked down the Ngb expression level using an siRNA technique and demonstrated that endogenous $\mathrm{Ngb}$ plays an important protective role in oxidative injuries by upregulating the expression of 14-3-3y, a protein that mediates essential apoptotic signaling ${ }^{[27,28]}$.

Our results demonstrate that the death of N2a/Ngb-siRNA cells increases following $\mathrm{H}_{2} \mathrm{O}_{2}$ treatment. An interesting finding is that the silencing of $\mathrm{Ngb}$ increases cell death with lower concentrations (150 and $300 \mu \mathrm{mol} / \mathrm{L}$ ) but not higher concentrations ( 450 and $600 \mu \mathrm{mol} / \mathrm{L}$ ) of $\mathrm{H}_{2} \mathrm{O}_{2}$. As estimated by microdialysis in the ischemic striatum, the concentration of $\mathrm{H}_{2} \mathrm{O}_{2}$ can rise as high as $100 \mu \mathrm{mol} / \mathrm{L}$ during the reperfusion phase $^{[29]}$. Our data supports a physiological or pathological role of endogenous $\mathrm{Ngb}$ in protecting cells from oxidative stress in the central nervous system. Moreover, we found that increased injury of N2a/Ngb-siRNA cells occurred within 30 min following $\mathrm{H}_{2} \mathrm{O}_{2}$-administration, indicating that $\mathrm{Ngb}$ has a direct protective effect against $\mathrm{H}_{2} \mathrm{O}_{2}$-induced cell damage.

Although the silencing of $\mathrm{Ngb}$ did not cause obvious cell death, it did induced caspase- 3 activation, indicating that endogenous $\mathrm{Ngb}$ suppresses apoptotic signal transduction pathways. This is consistent with the hypothesis proposed by Fago et al ${ }^{[30]}$ that $\mathrm{Ngb}$ increases the apoptosis-triggering threshold by maintaining cytochrome $\mathrm{C}$ in the nonapopotic ferrous oxidative state. Furthermore, we have identified an important apoptotic signaling protein ${ }^{[27]}$ through which $\mathrm{Ngb}$ may exert its anti-apoptotic function. 14-3-3y protein mediates essential apoptotic signaling pathways by binding to proapoptotic proteins such as Bad, Bax, ASK-1, and p53 ${ }^{[28]}$. We previously demonstrated that $14-3-3 \gamma$ is up-regulated in and protects astrocytes from ischemic injury ${ }^{[24,25]}$. In ischemic neurons, $\mathrm{Ngb}$ is up-regulated and exerts a protective role ${ }^{[11]}$. We propose that $\mathrm{Ngb}$ might exert its protection by regulating 14-3-3y expression in ischemic neurons. Considering that $\mathrm{Ngb}$ has a regulatory role for the G-protein ${ }^{[16,17]}$, it is likely that $\mathrm{Ngb}$ may control 14-3-3y expression through G-protein-mediated signaling. In addition to controlling 14-3-3y levels, Ngb may exert its protective role via other mechanisms such as lipid raft-mediated signaling ${ }^{[31]}$.

In conclusion, we are the first to demonstrate that the suppression of $\mathrm{Ngb}$ enhances neuronal vulnerability to oxidative injuries and that the underlying mechanism involved is 14-3-3y down-regulation.

\section{Acknowledgements}

The authors thank Prof Jian-zhi WANG for providing the N2a cell line. This work was supported by grants from the National Natural Science Foundation of China (№ 30470539 and 30570555) and NCET-05-0645 to Xiao-qian CHEN.

\section{Author contribution}

Xiao-qian CHEN designed research; Xin-yu ZHOU, Shi-qiao YE, Xiao-jing LAI, and Li ZHENG performed research; Xiaoqian CHEN and Shi-qiao YE wrote the paper.

\section{References}

1 Burmester T, Weich B, Reinhardt S, Hankeln T. A vertebrate globin expressed in the brain. Nature 2000; 407: 520-3.

2 Schmidt M, GiessI A, Laufs T, Hankeln T, Wolfrum U, Burmester T. How does the eye breathe? Evidence for neuroglobin-mediated oxygen supply in the mammalian retina. J Biol Chem 2003; 278: 1932-5.

3 Pesce A, Bolognesi M, Bocedi A, Ascenzi P, Dewilde S, Moens L, et al. Neuroglobin and cytoglobin: Fresh blood for the vertebrate globin family. EMBO Rep 2002; 3: 1146-51.

4 Trent JT, Watts RA, Hargrove MS. Human neuroglobin, a hexacoordinate hemoglobin that reversibly binds oxygen. J Biol Chem 2001; 276: 30106-10. 
5 Brunori M, Vallone B. A globin for the brain. FASEB J 2006; 20: 2192 7.

6 Nienhaus K, Nienhaus GU. Searching for neuroglobin's role in the brain. IUBMB Life 2007; 59: 490-7.

7 Herold S, Fago A, Weber RE, Dewilde S, Moens L. Reactivity studies of the $\mathrm{Fe}(\mathrm{III})$ and $\mathrm{Fe}(\mathrm{II}) \mathrm{NO}$ forms of human neuroglobin reveal a potential role against oxidative stress. J Biol Chem 2004; 279: 22841-7.

8 Brunori M, Giuffrè A, Nienhaus K, Nienhaus GU, Scandurra FM, Vallone B. Neuroglobin, nitric oxide, and oxygen: functional pathways and conformational changes. Proc Natl Acad Sci USA 2005; 102: 8483-8.

9 Hundahl CA, Kelsen J, Dewilde S, Hay-Schmidt A. Neuroglobin in the Rat Brain (II): Co-localisation with Neurotransmitters. Neuroendocrinology 2008; 88: 183-98.

10 Khan AA, Mao XO, Banwait S, Jin K, Greenberg DA. Neuroglobin attenuates beta-amyloid neurotoxicity in vitro and transgenic Alzheimer phenotype in vivo. Proc Natl Acad Sci USA 2007; 104: 19114-9.

11 Sun Y, Jin K, Mao XO, Zhu Y, Greenberg DA. Neuroglobin is upregulated by and protects neurons from hypoxic-ischemic injury. Proc Natl Acad Sci USA 2001; 98: 15306-11.

12 Fordel E, Geuens E, Dewilde S, Rottiers P, Carmeliet P, Grooten J, et al. Cytoglobin expression is upregulated in all tissues upon hypoxia: an in vitro and in vivo study by quantitative real-time PCR. Biochem Biophys Res Commun 2004; 319: 342-8.

13 Mammen PP, Shelton JM, Ye Q, Kanatous SB, McGrath AJ, Richardson $\mathrm{JA}$, et al. Cytoglobin is a stress-responsive hemoprotein that is expressed in the developing and adult brain. J Histochem Cytochem 2006; 54: 1349-61.

14 Schmidt-Kastner R, Haberkamp M, Schmitz C, Hankeln T, Burmester T. Neuroglobin mRNA expression after transient global brain ischemia and prolonged hypoxia in cell culture. Brain Res 2006; 1103: 17380.

15 Roesner A, Mitz SA, Hankeln T, Burmester T. Globins and hypoxia adaptation in the goldfish, Carassius auratus. FEBS J 2008; 275: 3633-43.

16 Wakasugi K, Nakano T, Morishima I. Oxidized human neuroglobin acts as a heterotrimeric Galpha protein guanine nucleotide dissociation inhibitor. J Biol Chem 2003; 278: 36505-12.

17 Watanabe S, Wakasugi K. Neuroprotective function of human neuroglobin is correlated with its guanine nucleotide dissociation inhibitor activity. Biochem Biophys Res Commun 2008; 369: 695-700.

18 Chen XQ, Qin LY, Zhang CG, Yang LT, Gao Z, Liu S, et al. Presence of neuroglobin in cultured astrocytes. Glia 2005; 50: 182-6.

19 Jin K, Mao XO, Xie L, Khan AA, Greenberg DA. Neuroglobin protects against nitric oxide toxicity. Neurosci Lett 2008; 430: 135-7.

20 Li RC, Morris MW, Lee SK, Pouranfar F, Wang Y, Gozal D. Neuroglobin protects PC12 cells against oxidative stress. Brain Res 2008; 1190: 159-66.

21 Peroni D, Negro A, Bähr M, Dietz GP. Intracellular delivery of Neuroglobin using HIV-1 TAT protein transduction domain fails to protect against oxygen and glucose deprivation. Neurosci Lett 2007; 421: 110-4.

22 Wang X, Liu J, Zhu H, Tejima E, Tsuji K, Murata Y, et al. Effects of neuroglobin overexpression on acute brain injury and long-term outcomes after focal cerebral ischemia. Stroke 2008; 39: 1869-74.

23 Li D, Chen XQ, Li WJ, Yang YH, Wang JZ, Yu AC. Cytoglobin upregulated by hydrogen peroxide plays a protective role in oxidative stress. Neurochem Res 2007; 32: 1375-80.

24 Chen XQ, Fung YW, Yu AC. Association of 14-3-3y and phosphorylated bad attenuates injury in ischemic astrocytes. J Cereb Blood Flow Metab 2005; 25: 338-47.

25 Chen XQ, Chen JG, Zhang Y, Hsiao WW, Yu AC. 14-3-3y is upregulated by in vitro ischemia and binds to protein kinase Raf in primary cultures of astrocytes. Glia 2003; 42: 315-24.

26 Ikonen M, Liu B, Hashimoto Y, Ma L, Lee KW, Niikura T, et al. Interaction between the Alzheimer's survival peptide humanin and insulinlike growth factor-binding protein 3 regulates cell survival and apoptosis. Proc Natl Acad Sci USA 2003; 100: 13042-7.

27 Dougherty MK, Morrison DK. Unlocking the code of 14-3-3. J Cell Sci 2004; 117: 1875-84.

28 Porter GW, Khuri FR, Fu H. Dynamic 14-3-3/client protein interactions integrate survival and apoptotic pathways. Semin Cancer Biol 2006; 16: 193-202.

29 Hyslop PA, Zhang Z, Pearson DV, Phebus LA. Measurement of striatal $\mathrm{H}_{2} \mathrm{O}_{2}$ by microdialysis following global forebrain ischemia and reperfusion in the rat: correlation with the cytotoxic potential of $\mathrm{H}_{2} \mathrm{O}_{2}$ in vitro. Brain Res 1995; 671: 181-6.

30 Fago A, Mathews AJ, Brittain T. A role for neuroglobin: resetting the trigger level for apoptosis in neuronal and retinal cells. IUBMB Life 2008; 60: 398-401.

31 Khan AA, Mao XO, Banwait S, DerMardirossian CM, Bokoch GM, Jin K, et al. Regulation of hypoxic neuronal death signaling by neuroglobin. FASEB J 2008; 22: 1737-47. 